\title{
Aortic stenosis calcium scoring in a racially mixed sample
}

\author{
Daniel Brito ${ }^{1}$, Igor Goykhman ${ }^{2}$, Kevin Bryan Lo ${ }^{3}$, Yaser Alhamshari ${ }^{1}$, Jorge Luis Peñalver ${ }^{3}$, \\ Francisco Aguilar $^{3}$, Eduardo Quintero ${ }^{3}$, Aditi Kalla ${ }^{1}$, Evan Friend ${ }^{1}$, Gregg S. Pressman ${ }^{1}$ \\ ${ }^{1}$ Institute for Heart and Vascular Health, Einstein Medical Center, Philadelphia, PA; ${ }^{2}$ Department of Radiology, Einstein \\ Medical Center, Philadelphia, PA; ${ }^{3}$ Department of Internal Medicine, Einstein Medical Center, Philadelphia, PA, USA
}

\begin{abstract}
Aortic stenosis (AS) is common and increasing in prevalence as the population ages. Using computed tomography (CT) to quantify aortic valve calcification (AVC) it has been reported that men have greater degrees of calcification than women among subjects with severe AS. These data, however, were derived in largely Caucasian populations and have not been verified in non-Caucasian subjects. This retrospective study identified 137 patients with severe AS who underwent valve replacement and had CT scans within 6 months prior to surgery. AVC scores were compared between men and women, both in the entire sample and in racial subgroups. $52 \%$ of subjects were male and $62.8 \%$ were non-Caucasian. Mean AVC score for the entire cohort was $3062.08 \pm 2097.87$ with a range of 428 -
\end{abstract}

Correspondence: Gregg S. Pressman, 3230 Levy Building, Einstein Medical Center, 5501 Old York Rd, Philadelphia, 19141 PA, USA.

Tel.+1.215.4568991. E-mail: pressmang@einstein.edu

Contributions: GSP conceived and provided guidance for the project; DB was the primary author; IG provided guidance on calcium scoring. The other authors were involved in data collection and analysis. All authors approved the final manuscript.

Conflict of interest: The authors declare no conflict of interest.

Ethics approval: This retrospective chart review study was approved by the Institutional Review Board of the Einstein Healthcare Network.

Consent for publication: not applicable.

Availability of data and materials: The datasets used and/or analyzed during the current study are available from the corresponding author on reasonable request.

Key words: Aortic valve calcium; severe aortic stenosis; computed tomography; gender differences.

Received for publication: 3 June 2020.

Accepted for publication: 28 July 2020.

${ }^{\circ}$ Copyright: the Author(s), 2020

Licensee PAGEPress, Italy

Monaldi Archives for Chest Disease 2020; 90:1429

doi: 10.4081/monaldi.2020.1429

This article is distributed under the terms of the Creative Commons Attribution Noncommercial License (by-nc 4.0) which permits any noncommercial use, distribution, and reproduction in any medium, provided the original author(s) and source are credited.
13,089. Gender differences in aortic valve calcification were found to be statistically significant with an average AVC score of $3646 \pm 2422$ in men and $2433 \pm 1453$ in women $(p=0.001)$. On multivariate analysis, gender remained significantly associated with AVC score both in the entire sample $(\mathrm{p}=0.014)$ and in the nonCaucasian subgroup $(\mathrm{p}=0.008)$. Mean AVA was significantly greater in males than females but this difference disappeared when AVA was indexed to BSA $(p=0.719)$. AVA was not different between racial groups $(p=0.369)$. In this research we observed that among subjects with severe AS men have higher AVC scores than women regardless of racial background. This is consistent with previous studies in predominantly Caucasian populations.

\section{Introduction}

Aortic stenosis (AS) is a major public health problem with rising incidence and prevalence as the population ages [1-3]. The standard way to diagnose AS is with echocardiography. However, in certain situations, particularly "low-flow low-gradient" AS, it can be difficult to distinguish between true severe AS and "pseudosevere" AS [4]. To resolve this difficulty, it has been suggested that calcium scoring by computed tomography (CT) scan can reliably determine the presence or absence of severe AS $[5,6]$. A key caveat is that threshold calcium scores differ between men and women. These thresholds were derived from a largely Caucasian population and have not been verified in non-Caucasian subjects [7].

In previous work looking at calcium scores in a broad sample of in- and out-patients with clinically indicated chest CTs (not limited to AS), we also observed gender differences in degree of aortic valve calcification (AVC). However, this was true only among Caucasian subjects [8]. We therefore undertook the current study to test the hypothesis that the gender difference in degree of calcification among subjects with severe AS would be present in Caucasian subjects but not others.

\section{Methods}

Retrospective chart review was performed to identify subjects with a history of surgical aortic valve replacement/repair between 2007 and 2015. Severity of aortic valve stenosis was defined using standard recommendations for echocardiographic assessment of aortic valve stenosis. Both subjects with classical severe aortic stenosis as well as those with low flow-low gradient severe aortic stenosis were included. Clinical judgment was applied for subjects who do not meet standard criteria for severe aortic stenosis. 164 patients were initially identified. Of these 137 had a CT scan within 
six months of valve replacement; they form the study sample. CT scans were performed for various clinical reasons in both the inpatient and outpatient setting. Demographic and clinical data were collected for each patient from electronic medical records. These included age, gender, ethnicity, body mass index, body surface area, blood pressure, heart rate, symptoms, New York Heart Association (NYHA) function class, history of coronary artery disease (CAD), hypertension (HTN), dyslipidemia, diabetes mellitus (DM), body surface area (BSA), kidney disease, and smoking status. Echocardiographic data were also collected including: aortic valve morphology, maximal velocity, VTI, peak and mean gradient, and area (by continuity equation); left ventricular outflow tract (LVOT) diameter, area, VTI, and maximum velocity; stroke volume; left ventricular ejection fraction (LVEF), and aortic dimensions (sinus of Valsalva, sinotubular junction and ascending aorta diameters). We also obtained dimensions of the interventricular septum, left ventricular posterior wall, left ventricular inner dimension in both systole and diastole, and presence (and degree) of aortic, mitral, and tricuspid valve regurgitation.

The CT examinations were performed using Brilliance iCT, (Philips Healthcare, Cleveland, OH, USA) or LightSpeed VCT (General Electric Healthcare, Milwaukee, WI, USA) scanners. Thin slices of $0.62 \mathrm{~mm}$ and $1.25 \mathrm{~mm}$ were generated, and images were examined utilizing a Synapse PACS system (Fujifilm Medical Systems, USA Inc.). Routine CT scans of the chest as well as ECG gated examinations for coronary calcium score were accepted for AVC analysis (Figure 1). This was conducted either manually or with the help of automatic software (IntelliSpace, Philips Healthcare). With the manual processing, the boundaries of each calcification were carefully delineated with calculation of the area (in $\mathrm{mm}^{2}$ ) and CT density (in Hounsfield units) for each slice containing a calcification. Multiplication of these values yielded the AVC score [9]. There was a strong correlation $(r=0.89)$ of the scores obtained from the automatic software and manually. The same method was applied for evaluation of mitral valve apparatus calcification (MVC).

The prevalence and density of AVC and MVC scores across race and gender were assessed. Data are presented as mean and standard deviation for continuous variables, and numbers and percentages

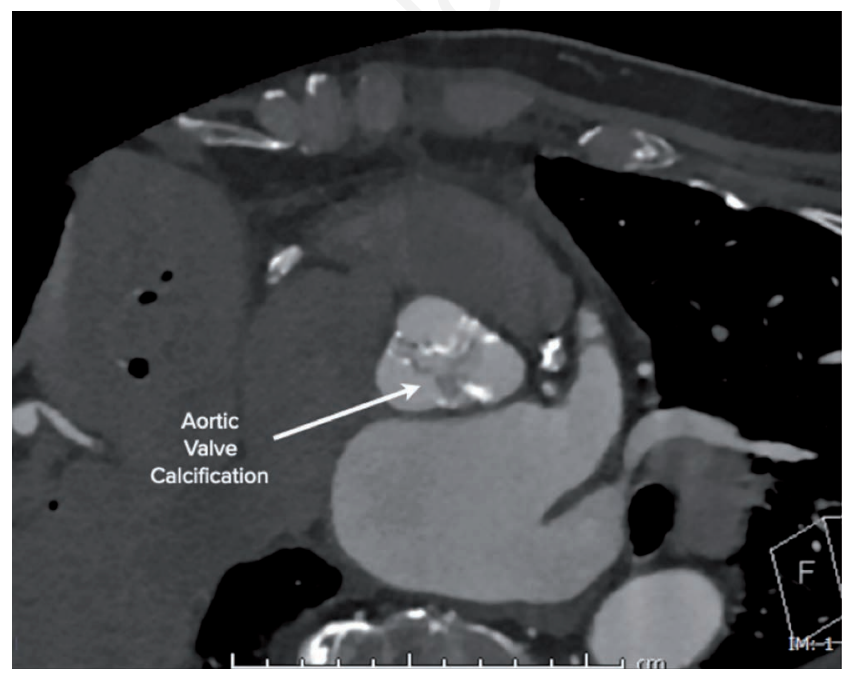

Figure 1. Cardiac computed tomography showing aortic valve calcification (AVC). for categorical variables. We compared AVC and MVC scores between men and women in i) the entire cohort, ii) non-Caucasian subjects, and iii) Caucasian subjects. As variances were roughly equally distributed, we used Student's $t$-test for these analyses. Nonparametric correlation (Spearman) was used to assess associations between AVC score and continuous variables (age, BSA, BMI). To test for an independent association between gender and AVC score we performed multivariate analysis controlling for various confounders (age, race, BSA, DM, HTN and CAD). A 2tailed $p$-value of $<0.05$ was statistically significant. Statistical analyses were performed using JMP, version 11.0 (SAS Institute, Cary, North Carolina). This study protocol conforms to the ethical guidelines of the 1975 Declaration of Helsinki as reflected in $a$ priori approval by the Institutional Review Board of the Albert Einstein Healthcare Network.

\section{Results}

The study included 137 subjects. Baseline characteristics are shown in Table 1. Half were male (52\%) and the majority were nonCaucasians (62.8\%). Among non-Caucasian subjects all but 11 were African American. Thus, separate analyses for specific racial groups were not performed. Hypertension was the most common comorbidity followed by hyperlipidemia, diabetes mellitus and COPD respectively. Mean aortic valve area (AVA) was significantly different between men and women; $0.80 \pm 0.19 \mathrm{~cm}^{2}$ vs $0.72 \pm 0.18$ $\mathrm{cm}^{2} ; \mathrm{p}=0.026$. However, this difference disappeared when AVA was indexed to BSA $(\mathrm{p}=0.719)$. Mean AVA was similar between Caucasian and non-Caucasian subjects; $0.76 \pm 0.21 \mathrm{~cm}^{2}$ vs $0.76 \pm 0.18$ $\mathrm{cm}^{2} ; \mathrm{p}=0.984$. There were also no significant differences between Caucasian and non-Caucasian subjects when AVA was indexed to $\operatorname{BSA}(\mathrm{p}=0.369)$.

The mean AVC score for the entire cohort was 3062.08 \pm 2097.87 with a range of 428-13,089. There were no significant differences in the mean AVC score between Caucasian and non-Caucasian subjects: $3315 \pm 2323$ vs $2911 \pm 1951, p=0.278$. However, gender differences in aortic valve calcification were found to be statistically significant with an average AVC score of $3646 \pm 2422$ in men and $2433 \pm 1453$ in women $(\mathrm{p}=0.001)$. We also analyzed our cohort according to previously published, gender-specific cutoffs for AVC score $[6,10]$. 102 of our 137 subjects (74\%) met the suggested "best" thresholds for determining the presence of severe aortic stenosis (1274 in women and 2065 in men). One hundred and eighteen (118) subjects (86\%) met a more liberal threshold (791 in women and 1661 in men) chosen to include $95 \%$ of subjects in the referenced study [6].

In non-Caucasian patients $(n=86)$ gender differences in AVC score were present and statistically significant (3577.84 \pm 2342.81 in men vs $2384.75 \pm 1384.95$ in women, $\mathrm{p}=0.004$, Table 2 ). Among Caucasian patients $(n=51)$ AVC scores were similarly different in males compared to females though the difference did not reach statistical significance (3724.67 \pm 2546.12 vs $2564.72 \pm 1659.11$, $\mathrm{p}=0.089$ ), possibly because of smaller sample size. Similar results were obtained when AVC score was indexed to BSA.

In comparisons of AVC score with various demographic and clinical variables, significant associations were found for gender $(p=0.002)$, BSA $(p=0.008)$, bisphosphonate use $(p=0.012)$ and insulin use $(\mathrm{p}=0.031)$. On multivariate analysis, after controlling for age, race, BSA, CKD, DM, HTN and smoking history, gender remained significantly associated with AVC score $(p=0.014)$. Interestingly, Bisphosphonate use was also found to be significantly associated with AVC score (Table 3 ) but only 4 subjects were taking 
bisphosphonates. When only the non-Caucasian subgroup was examined, gender was still significantly associated with AVC score $(\mathrm{p}=0.008)$.

Table 1. Baseline demographic and echocardiographic variables.

\begin{tabular}{|c|c|c|c|}
\hline n $(\%)$, mean \pm SD & $\begin{array}{l}\text { Males } \\
(\mathrm{n}=71) 52 \%\end{array}$ & $\begin{array}{l}\text { Females } \\
(n=66) 48 \%\end{array}$ & p value \\
\hline Age & $75.22 \pm 9.89$ & $79.69 \pm 11.35$ & 0.015 \\
\hline \multicolumn{4}{|l|}{ Ethnicity } \\
\hline Caucasian & $33(46.5 \%)$ & $18(27.3 \%)$ & 0.025 \\
\hline African American & $36(50.7 \%)$ & $39(59.1 \%)$ & \\
\hline Hispanic & $2(2.8 \%)$ & $6(9.1 \%)$ & \\
\hline Others & 0 & $3(4.5 \%)$ & \\
\hline Body surface area & $1.98 \pm 0.23$ & $1.79 \pm 0.24$ & $<0.0001$ \\
\hline Body mass index & $26.53 \pm 6.06$ & $28.7 \pm 7.6$ & 0.066 \\
\hline \multicolumn{4}{|l|}{ New York Heart Assoc. Class } \\
\hline I & $13(18.3 \%)$ & $12(18.2 \%)$ & 0.572 \\
\hline II & $11(15.5 \%)$ & $16(24.2 \%)$ & \\
\hline III & $31(43.7 \%)$ & $23(34.8 \%)$ & \\
\hline IV & $16(22.5 \%)$ & $15(22.7 \%)$ & \\
\hline Hypertension & $62(87.3 \%)$ & $59(89.4 \%)$ & 0.794 \\
\hline Dyslipidemia & $48(67.6 \%)$ & $44(66.7 \%)$ & 1.000 \\
\hline Diabetes & $32(45.1 \%)$ & $29(43.9 \%)$ & 1.000 \\
\hline COPD & $20(28.2 \%)$ & $20(30.3 \%)$ & 0.852 \\
\hline History of smoking & $22(31 \%)$ & $15(22.7 \%)$ & 0.337 \\
\hline CKD stage 3 and above & $27(38 \%)$ & $20(30 \%)$ & 0.372 \\
\hline Previous myocardial infarct & $34(47.9 \%)$ & $25(37.9 \%)$ & 0.300 \\
\hline Previous bypass surgery & $8(11.3 \%)$ & $6(9.1 \%)$ & 0.781 \\
\hline Previous PCI & $48(67.6 \%)$ & $41(62.1 \%)$ & 0.591 \\
\hline \multicolumn{4}{|l|}{ Medications } \\
\hline ACEi & $30(42.3 \%)$ & $19(28.8 \%)$ & 0.111 \\
\hline ARB & $3(4.2 \%)$ & $5(7.6 \%)$ & 0.481 \\
\hline Beta blocker & $47(66.2 \%)$ & $41(62.1 \%)$ & 0.722 \\
\hline Calcium channel blocker & $15(21.1 \%)$ & $18(27.7 \%)$ & 0.426 \\
\hline Diuretics & $29(40.8 \%)$ & $30(45.5 \%)$ & 0.608 \\
\hline Statins & $48(67.6 \%)$ & $47(72.3 \%)$ & 0.580 \\
\hline Other antilipids & $4(5.6 \%)$ & $2(3.1 \%)$ & 0.682 \\
\hline Oral hypoglycemics & $3(4.2 \%)$ & $5(7.7 \%)$ & 0.479 \\
\hline Insulin & $28(39.4 \%)$ & $19(28.8 \%)$ & 0.211 \\
\hline Antiplatelets & $48(67.6 \%)$ & $45(68.2 \%)$ & 1.000 \\
\hline Anticoagulants & $13(18.3 \%)$ & $10(15.2 \%)$ & 0.654 \\
\hline Bisphosphonates & $2(2.8 \%)$ & $2(3 \%)$ & 1.000 \\
\hline Calcium & $5(7 \%)$ & $10(15.2 \%)$ & 0.173 \\
\hline Vitamin D & $9(12.7 \%)$ & $14(21.2 \%)$ & 0.253 \\
\hline
\end{tabular}

Eighty-two patients had data available for mitral valve Agatston calcium score (MVC). The mean MVC score for the entire cohort was $1600.53 \pm 2810.94$ with a range of $10.54-19726$. There were

\begin{tabular}{|c|c|c|c|}
\hline n (\%), mean \pm SD & $\begin{array}{l}\text { Males } \\
(\mathrm{n}=71) 52 \%\end{array}$ & $\begin{array}{l}\text { Females } \\
(n=66) 48 \%\end{array}$ & $\mathrm{p}$ value \\
\hline \multicolumn{4}{|l|}{ Echocardiographic data } \\
\hline \multicolumn{4}{|l|}{ Aortic valve morphology } \\
\hline Tricuspid & $47(66.2 \%)$ & $53(81.5 \%)$ & \multirow[t]{3}{*}{0.08} \\
\hline Bicuspid & $2(2.8 \%)$ & & \\
\hline Unknown & $22(31 \%)$ & $12(18.5 \%)$ & \\
\hline LVOT diameter (mm) & $1.98 \pm 0.16$ & $1.90 \pm 0.15$ & 0.003 \\
\hline LVOT area $\left(\mathrm{cm}^{2}\right)$ & $3.09 \pm 0.51$ & $2.85 \pm 0.44$ & 0.003 \\
\hline LVOT VTI $(\mathrm{cm})$ & $20.21 \pm 6.5$ & $21.34 \pm 6.42$ & 0.310 \\
\hline LVOT Vmax $(\mathrm{cm} / \mathrm{s})$ & $94.1 \pm 27.56$ & $97.67 \pm 23.94$ & 0.420 \\
\hline Stroke volume & $61.24 \pm 18.16$ & $60.19 \pm 18.89$ & 0.741 \\
\hline Stroke volume index & $31.35 \pm 9.99$ & $33.98 \pm 10.64$ & 0.137 \\
\hline Aortic valve $\operatorname{Vmax}(\mathrm{cm} / \mathrm{s})$ & $367.73 \pm 76.70$ & $387.14 \pm 78.64$ & 0.068 \\
\hline Aortic Valve VTI (cm) & $79.23 \pm 20.26$ & $85.51 \pm 25.82$ & 0.114 \\
\hline Peak gradient (mmHg) & $58.37 \pm 20.53$ & $65.05 \pm 24.71$ & 0.087 \\
\hline Mean gradient (mmHg) & $34.97 \pm 13.1$ & $38.59 \pm 15.97$ & 0.148 \\
\hline AVA (cm2) & $0.80 \pm 0.19$ & $0.72 \pm 0.18$ & 0.026 \\
\hline AVA calculated $\left(\mathrm{cm}^{2}\right)$ & $0.79 \pm 0.19$ & $0.73 \pm 0.19$ & 0.062 \\
\hline AVAi & $0.41 \pm 0.10$ & $0.42 \pm 0.11$ & 0.719 \\
\hline AVAi calculated & $0.40 \pm 0.10$ & $0.41 \pm 0.11$ & 0.747 \\
\hline Ao Valsalva sinus diameter & $31.08 \pm 5.18$ & 28.21 & $<0.0001$ \\
\hline Ao STJ diameter (mm) & $25.17 \pm$ & $22.8 \pm$ & $<0.0001$ \\
\hline Ao Ascending diameter (mm) & $31.0 \pm$ & 28.7 & 0.008 \\
\hline IVSd ( & $12.13=$ & 12.5 & 0.384 \\
\hline IVSs & $16.8 \pm$ & 17.67 & 0.163 \\
\hline LVPWd & $12.06 \pm$ & 12.21 & 0.727 \\
\hline LVPWs & 17.3 & $17.47 \pm 3.63$ & 0.899 \\
\hline LVd ( & $46.75 \pm$ & $43.35 \pm 7.01$ & 0.014 \\
\hline LVs (mm) & $34.25 \pm 9.35$ & $28.24 \pm 8.32$ & $<0.0001$ \\
\hline LVEF (\%) & $47.79 \pm 15.23$ & $55.91 \pm 12.73$ & 0.001 \\
\hline \multicolumn{4}{|l|}{ Aortic regurgitation } \\
\hline None/trace & $41(57.7 \%)$ & $38(57.6 \%)$ & \multirow{4}{*}{0.691} \\
\hline Mild & $20(28.2 \%)$ & $20(30.3 \%)$ & \\
\hline Moderate & $10(14.1 \%)$ & $7(10 / 6 \%)$ & \\
\hline Severe & 0 & $1(1.5 \%)$ & \\
\hline \multicolumn{4}{|l|}{ Mitral regurgitation } \\
\hline None/trace & $35(49.3 \%)$ & $35(53 \%)$ & \multirow[t]{4}{*}{0.588} \\
\hline Mild & $27(38 \%)$ & $20(30.3 \%)$ & \\
\hline Moderate & $9(12.7 \%)$ & $11(16.7 \%)$ & \\
\hline Severe & 0 & 0 & \\
\hline \multicolumn{4}{|l|}{ Tricuspid regurgitation } \\
\hline None/trace & $45(63.4 \%)$ & $34(51.5 \%)$ & \multirow[t]{4}{*}{0.393} \\
\hline Mild & $17(23.9 \%)$ & $17(25.8 \%)$ & \\
\hline Moderate & $8(11.3 \%)$ & $14(21.2 \%)$ & \\
\hline Severe & $1(1.4 \%)$ & $1(1.5 \%)$ & \\
\hline Mitral Agatston score & $1636.11 \pm 3768.79$ & $1578.90 \pm 2068.01$ & 0.929 \\
\hline Aortic Agatston score & $3646.09 \pm 2422.84$ & $2433.83 \pm 1453.74$ & $<0.000$ \\
\hline
\end{tabular}

COPD, chronic obstructive pulmonary disease; CKD, chronic kidney disease; PCI, percutaneous coronary intervention; ACEi, angiotensin converting enzyme inhibitor; ARB, angiotensin receptor blocker; LVOT, left ventricular outflow tract; VTI-velocity time integral; Vmax-maximum velocity; AVA, aortic valve area; AVAi, aortic valve area index; Ao, aortic; STJ, sinotubular junction; IVSd, Interventricular septal end diastole and end systole(IVSs); LVPW, Left ventricular posterior wall thickness at end -diastole; end systole (LVPWs); LVd, left ventricular diameter diastole; LVs, left ventricular diameter systole; LVEF, left ventricular ejection fraction.

Table 2. Comparison of mean aortic Agatston score between gender and ethnic groups.

\begin{tabular}{lccc} 
& Male $(\mathrm{n}=7 \mathbf{1})$ & Female $(\mathrm{n}=66)$ & p value \\
Caucasian & $3724.67 \pm 2546.12(\mathrm{n}=33)$ & $2564.72 \pm 1659.11(\mathrm{n}=18)$ & 0.089 \\
Non-Caucasian & $3670.22 \pm 2303.90(\mathrm{n}=37)$ & $2384.75 \pm 1384.95(\mathrm{n}=48)$ & 0.002 \\
\hline $\mathrm{p}$ value & 0.801 & 0.658 & \\
\hline
\end{tabular}


significant differences in the mean MVC score between Caucasian and non-Caucasians $2726.62 \pm 3973.67$ vs $802.88 \pm 981.59$ ( $\mathrm{p}=0.02$ ). This was apparent even in analysis of Caucasian females vs nonCaucasian females $(p=0.0001)$ but was not present in males $(p=0.189$, Table 4$)$. In contrast to the AVC findings above, no gender differences independent of ethnicity in mitral valve calcification were found with mean MVC score of $1636.11 \pm 3768.79$ in men and $1578.90 \pm 2068.01$ in women $(\mathrm{p}=0.929)$. In non-Caucasian patients $(n=48)$ MVC score was lower in males than in females but this was not statistically significant $(\mathrm{p}=0.484$, Table 4$)$. Among Caucasian patients ( $\mathrm{n}=34)$ MVC scores were also lower in males compared to females but the difference was not statistically significant $(\mathrm{p}=0.693$, Table 4). On correlational analysis, MVC was associated with race $(\mathrm{p}=0.008)$ alone. With multivariate regression, only race was significantly associated with MVC ( $\mathrm{p}=0.003)$ (Table 5).

\section{Discussion}

Calcium load in the stenotic aortic valve can be precisely quantitated by multi-detector CT. The resultant AVC scores have

Table 3. Multivariate regression on factors associated with aortic valve Agatston score.

\begin{tabular}{lccc} 
Variable & Beta & 95\% Confidence interval & P value \\
$\begin{array}{l}\text { Age } \\
\text { Referrant }\end{array}$ & -13.58 & -47.83 to 20.68 & 0.434 \\
$\begin{array}{l}\text { Female } \\
\text { Referrant }\end{array}$ & -930.43 & -1668.68 to -192.20 & 0.014 \\
\hline African American & & -722.13 to 707.37 & 0.984 \\
Hispanic & -7.38 & -1387.08 to 1697.30 & 0.843 \\
\hline Others & 155.11 & -2744.89 to 1971.61 & 0.746 \\
Body surface area & -386.69 & 34.15 to 3010.13 & 0.045 \\
\hline Diabetes & 1522.14 & -1463.03 to 174.43 & 0.122 \\
Hypertension & -644.30 & -1381.81 to 783.69 & 0.586 \\
\hline Smoking history & -299.06 & -771.82 to 786 & 0.986 \\
Chronic kidney disease & 7.09 & -1013.21 to 420.53 & 0.415 \\
\hline Bisphosphonates use & -296.34 & 1488.61 to 5473.84 & 0.001 \\
Insulin use & 3481.23 & -1228.95 to 395.43 & 0.312 \\
\hline
\end{tabular}

Table 4. Comparison of mean mitral Agatston score between gender and ethnic groups.

\begin{tabular}{lccc} 
& Male $(\mathrm{n}=\mathbf{3 1})$ & Female $(\mathrm{n}=\mathbf{5 1})$ & p value \\
Caucasian & $2451.20 \pm 4940.04(\mathrm{n}=17)$ & $3002.05 \pm 2828.72(\mathrm{n}=17)$ & 0.693 \\
Non-Caucasian & $646.36 \pm 907.73(\mathrm{n}=14)$ & $867.33 \pm 1017.42(\mathrm{n}=34)$ & 0.484 \\
\hline p value & 0.189 & 0.0001 & \\
\hline
\end{tabular}

Table 5. Multivariate regression on factors associated with mitral valve Agatston score.

\begin{tabular}{|c|c|c|c|}
\hline Variable & Beta & $95 \%$ Confidence interval & p value \\
\hline $\begin{array}{l}\text { Age } \\
\text { Referrant }\end{array}$ & 19.08 & -40.27 to 78.42 & 0.523 \\
\hline $\begin{array}{l}\text { Female } \\
\text { Referrant }\end{array}$ & 755.79 & -680.52 to 2192.1 & 0.298 \\
\hline African American & -2054.57 & -3373.95 to -735.19 & 0.003 \\
\hline Hispanic & -2260.63 & -5353.97 to 832.702 & 0.149 \\
\hline Others & -2393.42 & -5802.79 to 1015.95 & 0.166 \\
\hline Body surface area & 2081.86 & -1115.39 to 5279.12 & 0.198 \\
\hline Diabetes & 1414.62 & -114.63 to 2943.86 & 0.069 \\
\hline Hypertension & -1730.52 & -3953.49 to 492.46 & 0.125 \\
\hline Smoking history & -0.825 & -1447.24 to 1445.59 & 0.999 \\
\hline Chronic kidney disease & 365.39 & -976.45 to 1707.23 & 0.589 \\
\hline Bisphosphonates use & -911.68 & -4143.98 to 2320.63 & 0.575 \\
\hline Insulin use & -1367.90 & -2869.49 to 133.70 & 0.0740 \\
\hline
\end{tabular}


been correlated with the weight of valves excised at the time of surgery [10], and have prognostic value [11]. Recent work has shown that, for the same degree of stenosis, men and women have differing calcium burdens. This has led to the proposal of genderspecific cutoffs for identification of severe AS [6]. CT measurement of calcium burden can be particularly useful in assessing AS severity when stroke volume is reduced and transvalvular gradients are low [7]. However, these studies have all involved predominantly Caucasian subjects. To our knowledge, the current research is the first to extend these observations to a racially diverse population.

Calcification of the aortic valve occurs at early stages of the disease, characterized by an active inflammatory process that shares similarities with atherosclerosis [12]. The association between accumulation of calcium and severity of AS has been amply demonstrated both by autopsy and CT. Aggarwal et al. were the first to convincingly demonstrate differences in AVC load between men and women with aortic stenosis [7]. While these differences were minimal at earlier stages of the disease, they became greater as disease severity increased. Further, differences in degree of valvular calcification remained after normalization for body surface area and cross-sectional area of the aortic annulus. While the pathophysiology behind these differences remains unclear, there are other examples of gender differences in various cardiac disease states. For instance, it has been noted that men have greater degrees of coronary artery calcification than women [13]. Additionally, there are gender differences in adaptation of the left ventricle to aortic stenosis $[14,15]$ and patterns of hypertrophy $[16,17]$ differ between the genders. In the case of calcific aortic stenosis, it has been postulated that women have greater degrees of valvular fibrosis and less intense calcification of the valve as compared to men [7].

We previously investigated differences in pattern and degree of cardiac calcification between men and women, and different racial groups [8]. Looking at subjects with any degree of AVC (as opposed to the current study which focused only on subjects with severe AS) we observed higher AVC scores in men versus women, but only among Caucasian subjects. Non-Caucasian subjects showed similar degrees of AVC in men and women. Based on this we hypothesized that the published gender-specific calcium thresholds for determination of severe AS [6] might only apply to Caucasian patients. The current findings refute that hypothesis. Severe AS appears to occur at lower calcium scores in women versus men regardless of race.

This work was retrospective and is subject to all the associated limitations. However, it reflects a diverse patient sample including a large number of women and minority patients, similar to what is encountered in many urban settings. This study was not designed to detect a cut-off value for severe AS. That would require studying a large series of patients with varying degrees of AS. Rather, we measured calcium scores in patients determined to have severe AS (as indicated by the need for valve replacement) and compared those scores between Caucasian subjects (for whom cutoffs have been determined) and non-Caucasian subjects. In addition, our patients fell largely within previously validated ranges of AVC score that have been associated with severe AS. While our sample size is not large enough to confirm published gender-specific thresholds, our results are consistent with them.

In conclusion, among subjects with severe AS men have a higher calcium burden than women for the same severity of stenosis. This difference occurs among non-Caucasian as well as Caucasian subjects.

\section{References}

1. Eveborn GW, Schirmer H, Heggelund G, et al. The evolving epidemiology of valvular aortic stenosis. The Tromso study. Heart 2013;99:396-400.

2. Lin SL, Liu CP, Young ST, et al. Age-related changes in aortic valve with emphasis on the relation between pressure loading and thickened leaflets of the aortic valves. Int $\mathrm{J}$ Cardiol 2005;103:272-9.

3. Nkomo VT, Gardin JM, Skelton TN, et al. Burden of valvular heart diseases: a population-based study. Lancet 2006;368:1005-11.

4. Pibarot P, Dumesnil JG. Low-flow, low-gradient, normal ejection fraction aortic stenosis. Curr Cardiol Rep 2010;12:108-15.

5. Messika-Zeitoun D, Aubry MC, Detaint D, et al. Evaluation and clinical implications of aortic valve calcification measured by electron-beam computed tomography. Circulation 2004;110: 356-62.

6. Clavel MA, Messika-Zeitoun D, Pibarot P, et al. The complex nature of discordant severe calcified aortic valve disease grading: new insights from combined Doppler echocardiographic and computed tomographic study. J Am Coll Cardiol 2013;62: 2329-38.

7. Aggarwal SR, Clavel MA, Messika-Zeitoun D, et al. Sex differences in aortic valve calcification measured by multidetector computed tomography in aortic stenosis. Circ Cardiovasc Imaging 2013;6:40-7.

8. Koshkelashvili N, Codolosa JN, Goykhman I, et al. Distribution of Mitral Annular and Aortic Valve Calcium as Assessed by Unenhanced Multidetector Computed Tomography. Am J Cardiol 2015;116:1923-7.

9. Agatston AS, Janowitz WR, Hildner FJ, et al. Quantification of coronary artery calcium using ultrafast computed tomography. J Am Coll Cardiol 1990;15:827-32.

10. Clavel MA, Pibarot P, Messika-Zeitoun D, et al. Impact of aortic valve calcification, as measured by MDCT, on survival in patients with aortic stenosis: results of an international registry study. J Am Coll Cardiol 2014;64:1202-13.

11. Thaden JJ, Nkomo VT, Suri RM, et al. Sex-related differences in calcific aortic stenosis: correlating clinical and echocardiographic characteristics and computed tomography aortic valve calcium score to excised aortic valve weight. Eur Heart J 2016;37:693-9.

12. Otto CM, Kuusisto J, Reichenbach DD, et al. Characterization of the early lesion of 'degenerative' valvular aortic stenosis. Histological and immunohistochemical studies. Circulation 1994;90:844-53.

13. Bild DE, Detrano R, Peterson D, et al. Ethnic differences in coronary calcification: The Multi-Ethnic Study of Atherosclerosis (MESA). Circulation 2005;111:1313-20.

14. Carroll JD, Carroll EP, Feldman T, et al. Sex-associated differences in left ventricular function in aortic stenosis of the elderly. Circulation 1992;86:1099-107.

15. Milavetz DL, Hayes SN, Weston SA, et al. Sex differences in left ventricular geometry in aortic stenosis: impact on outcome. Chest 2000;117:1094-9.

16. Kostkiewicz M, Tracz W, Olszowska M, et al. Left ventricular geometry and function in patients with aortic stenosis: gender differences. Int J Cardiol 1999;71:57-61.

17. da Rocha AS, Pereira MA, Rocha Nde N, et al. Aortic stenosis. Gender influence on left ventricular geometry and function in patients under 70 years of age. Arq Bras Cardiol 1999;72:475-82. 